\title{
Eu sou racista: uma análise discursiva sobre o imbricamento de posições- sujeito
}

I am racist: a discursive analysis on the overlapping of subject positions

\author{
Isabel Cristiane Jerônimo ${ }^{1(\mathbb{D})}$ \\ ${ }^{1}$ Universidade Estadual de Londrina (UEL), Brasil, Doutora em Letras (Unesp), docente do departamento de letras vernáculas \\ (UEL), e-mail: cristianejeronimo@terra.com.br
}

\begin{abstract}
RESUMO
Os embates raciais envolvendo negros e brancos estão presentes na estrutura da sociedade brasileira, em suas instituições, no cotidiano das interações interpessoais, na mídia, sempre materializados em discursos dispersos no tempo e no espaço, circulando socialmente. Pontualmente, a imprensa constituise como um aparelho ideológico importante em que questões raciais costumam ser apresentadas a partir de diferentes vieses nos gêneros jornalísticos que a compõem. Mobilizando conceitos pertencentes à Análise do discurso de linha francesa na perspectiva pêcheutiana, pretende-se investigar o funcionamento de um discurso produzido em âmbito jornalístico em que o sujeito discursivo se subjetiva como racista. De que forma o sujeito discursivo constrói o sentido da palavra "racista"? Como esse sujeito é afetado pela linguagem, pela ideologia e pelo inconsciente ao tratar da questão racial? De que posições esse sujeito enuncia e a quais formações discursivas e ideológicas vincula-se? Num país que nega o seu racismo diariamente, em que esse tipo de atitude é sempre atribuído ao outro, um discurso no qual o sujeito se subjetiva como racista merece atenção. Em "Eu sou racista", pretendemos analisar os modos de constituição desse sujeito implicado em relações históricas e ideológicas conflituosas, muitas vezes marcadas por formações discursivas contraditórias, já que o próprio caráter estrutural do racismo é um fator determinante para a flutuação das posições-sujeito na constituição do discurso e para o deslizamento de sentidos.
\end{abstract}

Palavras-chave: Racismo. Condições de produção. Posições-sujeito.

\begin{abstract}
Racial conflicts involving black and white people are present in the structure of Brazilian society, in its institutions, in the daily life of interpersonal interactions, in the media, those conflicts are always materialized in discourses dispersed in time and space, circulating socially. Occasionally, the press is an important ideological apparatus in which racial issues are usually presented from different biases in the journalistic genres that compose it. By mobilizing concepts belonging to the Discourse Analysis of the French line in the Pêcheux's perspective, it is intended to investigate the functioning of a discourse produced in a journalistic scope that the discursive subject subjectifies as a racist. How does the discursive subject build the meaning of the word "racist"? How is this subject affected by the language, the ideology and the unconscious when dealing with racial issue? What positions does this subject enunciate and to which discursive and ideological formations does he link? In a country that denies its racism daily, in which this type of attitude is always attributed to the other, a discourse in which the subject subjectifies as a racist deserves attention. In "I'm racist", we intend to analyze the ways of constitution of this subject involved in conflicting historical and ideological relations, often marked by contradictory discursive formations, since the very structural character of racism is a determining factor for the fluctuation of subject positions in the constitution of the speech and for the sliding of meanings.
\end{abstract}

Keywords: Racism. Conditions of production. Subject positions. 


\section{INTRODUÇÃO}

A proposta deste trabalho é observar o funcionamento de um discurso em que questões raciais entre negros e brancos estão em primeiro plano. Elegemos como materialidade discursiva para análise um texto extraído do jornal Folha de S. Paulo em que a colunista, Tati Bernardi, enuncia em seu título Eu sou racista. Como questões de pesquisa que regem nossa análise temos: Que condições sócio-históricas possibilitam a existência desse dizer nos dias atuais? De que forma esse sujeito é afetado pela linguagem, pela ideologia e pelo inconsciente ao tratar da questão racial? Que posições-sujeito ocupa para manifestar-se no polêmico jogo das relações raciais?

As discussões a respeito desse tema são sempre necessárias, visto que o racismo no país parece não arrefecer e configura-se de diferentes formas, mais ou menos explícitas. Somente uma análise discursiva pode chegar aos aspectos histórico e ideológico que determinam as formulações do discurso e desvelar seu funcionamento, já que enunciado e discurso são coisas diferentes. Levando-se em conta que para a Análise de discurso não há transparência da linguagem e que o sentido sempre pode deslizar, tornando-se outro, estaremos atentos para como a ideia do que é ser racista é constituída pelo sujeito, o qual se constitui como efeito de linguagem enunciando em condições de produção específicas.

O trabalho compõe-se, primeiramente, da fundamentação teórica relativa às discussões sociológicas a respeito de conceitos ligados a questões raciais; em seguida, apresentaremos alguns conceitos da Análise de discurso que compõem o dispositivo teórico para alcançarmos o objetivo pretendido. Em seguida, apresentaremos a análise, a discussão dos resultados e as considerações finais.

\section{REFERENCIAL TEÓRICO}

\subsection{APONTAMENTOS SOBRE RAÇA, RACISMO, RACISTA}

Como o corpus de análise deste trabalho diz respeito ao funcionamento de um discurso situado em condições de produção sócio-históricas que se referem à discussão racial (a saber, relações entre negros e não brancos no Brasil), é preciso que se teça uma breve contextualização acerca de termos essenciais que constituem esse complexo universo.

Revista Expectativa, Toledo/PR, v.20, n. 2, p. 116-134, abr./jun., 2021. 
Há algum tempo, mais precisamente desde a segunda metade do século XX, a noção de raça, pelo prisma científico, é um conceito que já não se sustenta, ou seja, para a ciência fenótipos distintos são características ínfimas e insuficientes para se afirmar que um grupo de indivíduos faz parte de uma espécie diferente, já que geneticamente somos todos muito próximos. A pequena porcentagem de genes que se distinguem (responsáveis pela aparência física ou pela cor da pele, por exemplo) não justifica a classificação da sociedade em raças. Essas diferenças são resultado da adaptação dos indivíduos aos diferentes ambientes pelos quais a espécie humana transitou em seu processo de evolução. A conclusão de que a raça não é um marcador genético corrige o erro histórico dos cientistas do passado que se valiam do determinismo racial para marcar raças superiores e inferiores e legitimar a dominação.

No Brasil, contudo, último país a abolir a escravidão nas Américas, há uma prática curiosa em que se elegem as ideias "que pegam" e as que "não pegam", dependendo das relações de forças sociais e dos conflitos de interesses envolvidos. O discurso científico que afirma a nulidade da ideia de raças "não pegou" para grande parte do imaginário coletivo. Como nos lembra Munanga (2017), a racionalidade não é suficiente para que as pessoas abram mão de suas crenças racistas, ou seja, os racistas não são movidos por comprovações científicas. No cotidiano da sociedade brasileira, a construção social responsável pela propagação do conceito permanece viva, bem como as práticas discriminatórias anti-negro a ele relacionadas. É o resultado de um longo processo histórico que envolve, muito especificamente, os sujeitos possuidores de pele escura e de outros traços marcados física e socialmente.

Nas práticas discursivas, quando lidamos com as palavras e seus efeitos de sentidos, como no caso de "raça", é preciso levar em conta, como nos lembra Hall (1995, p.2) que:

\footnotetext{
Não é possível fixar o sentido de um significante para sempre ou trans-historicamente. Ou seja, há sempre um certo deslizamento do sentido, há sempre uma margem ainda não encapsulada na linguagem e no sentido, sempre algo relacionado com raça que permanece não dito, alguém é sempre o lado externo constitutivo, de cuja existência a identidade de raça depende, e que tem como destino certo voltar de sua posição de expelido e abjeto, externo ao campo da significação, para perturbar os sonhos de quem está à vontade do lado de dentro.
}

Nesse sentido, migrando da perspectiva biológica para uma visão antropológica, Munanga (2003, p.6) afirma que raça "é um conceito carregado de ideologia, pois como todas as ideologias, ele esconde uma coisa não proclamada: a relação de poder e de dominação. A raça, sempre apresentada como categoria biológica é, de fato, uma categoria etnosemântica". Ou seja, é um conceito intimamente relacionado às questões de poder presentes na sociedade, 
uma categoria que pode ser utilizada para perpetuar a dominação e a exclusão. Raça, no Brasil, ainda é algo relevante.

Em decorrência do conceito de raça, e dos traços ideológicos que o circundam, temos a prática do racismo a ele associada. Talvez, as práticas discriminatórias tenham gerado a noção, a fim de legitimá-las. Wieviorka (2007, p.9) define racismo como "a caracterização de um conjunto humano pelos atributos naturais associados a características intelectuais e morais que valem para cada indivíduo dependente desse conjunto e, a partir disso, o colocar eventualmente em execução práticas de inferiorização e exclusão.” Para Almeida (2019, p.50), constitui-se como parte da estrutura do país: "O racismo é decorrência da própria estrutura social, ou seja, do modo "normal" com que se constituem as relações políticas, econômicas, jurídicas, e até familiares, não sendo uma patologia social, nem um desarranjo institucional. O racismo é estrutural."

Perceber o racismo como "norma" não é uma forma de banalizar o conceito, mas de ajudar a explicar sua dinâmica, as condições de dominação e sua função política. Essa normalização faz com que grande parte da população entenda como natural, ou apenas como uma característica cultural, a ausência de pessoas negras em espaços de poder e negros em profusão em presídios ou ocupando lugares sociais pouco valorizados. Perplexidade quando exceções conseguem romper os mecanismos de exclusão.

Munanga (2003, p.7-8) apresenta uma definição de racismo que dialoga com as anteriores e acrescenta, ainda no mesmo campo de relação de sentidos, uma reflexão sobre o pensar do sujeito racista:

\footnotetext{
Visto deste ponto de vista, o racismo é uma crença na existência das raças naturalmente hierarquizadas pela relação intrínseca entre o físico e o moral, o físico e o intelecto, o físico e o cultural. O racista cria a raça no sentido sociológico, ou seja, a raça no imaginário do racista não é exclusivamente um grupo definido pelos traços físicos. A raça na cabeça dele é um grupo social com traços culturais, linguísticos, religiosos, etc. que ele considera naturalmente inferiores ao grupo ao qual ele pertence. De outro modo, o racismo é essa tendência que consiste em considerar que as características intelectuais e morais de um dado grupo, são consequências diretas de suas características físicas ou biológicas.
}

Esse racismo "sociológico" está condicionado a uma identidade brasileira construída como um país miscigenado, locus da democracia racial em que negros e brancos viveriam de maneira harmônica, sem graves conflitos, herdada de uma memória falsamente construída de que a escravidão no Brasil teria sido mais aprazível que a dos Estados Unidos por não termos 
tido, por exemplo, leis de segregação racial. O racismo à brasileira, caracterizado como cordial, não tem rosto, finge garantir simetria legal a todos, bem como uma suposta universalidade e discrimina de forma silenciosa, privada (SCHWARCZ, 1998).

Além disso, como afirma Florestan Fernandes (2013, p.20) “O que há de mais evidente nas atitudes dos brasileiros diante do "preconceito de cor" é a tendência a considerá-lo algo ultrajante (para quem o sofra) e degradante (para quem o pratica)". Entretanto, apesar de esse ser interpretado como um ato odioso, grande parte dos brasileiros continua discriminando, mas jura desconhecer-se como agente do racismo. É uma prática discursiva envergonhada, cruel e persistente, passível de punição legal ${ }^{1}$, embora eventuais punições jurídicas não coíbam a continuidade da discriminação racial. Segundo Muniz Sodré (2019, p.878), “Aboliu-se, o racismo de segregação, mas não se aboliu o de dominação. $O$ de dominação é esse que se faz por sutilezas."

O discurso racista brasileiro diz que ser branco nesta sociedade é ocupar uma posição de sujeito nas práticas sociais que corresponde ao elemento não marcado, ao sujeito universal. A branquitude corresponde ao não étnico, ao neutro da humanidade, via de acesso facilitadora às estruturas políticas, econômicas e jurídicas. Já o "ser negro" permanece como sinônimo de subalternidade pela historicidade construída, vítima do que Munanga (2017, p.40) denominou de crime perfeito: "o racismo, além de matar fisicamente, alija pelo silêncio a consciência das vítimas e da sociedade como um todo".

Para concluir, abordar a questão do racismo nos obriga a relacioná-lo à variável classe social dentro do contexto capitalista. Retrocedendo no tempo para podermos avançar, Domingues (2004, p.106) afirma:

\begin{abstract}
Quando enfocamos a dinâmica da inserção do negro na sociedade de classes na Primeira República em São Paulo, aventamos a hipótese de que as práticas racistas discriminatórias e as desigualdades raciais plasmaram o processo de organização do trabalho livre, gerando o banimento dos negros das velhas relações de trabalho e impedindo-lhes o acesso às novas oportunidades de emprego.
\end{abstract}

Ontem e hoje, o racismo serve ao capitalismo, pois divide a classe trabalhadora e destina à população negra as piores condições de trabalho, funciona de modo dinâmico para a manutenção e para a reprodução do capital. As relações de produção reproduzem as

\footnotetext{
${ }^{1}$ A tipificação do racismo como crime (artigo 5º, inciso XLII, da Constituição Federal de 1988; artigo 20 da Lei n. 7.716/1989, e artigo 60 da Lei n. 12.228/2010).
}

Revista Expectativa, Toledo/PR, v.20, n. 2, p. 116-134, abr./jun., 2021. 
desigualdades, tanto as que propiciam a alienação do produto do trabalho e do trabalhador, quanto aquelas que no interior dessas relações fomentam e constroem a discriminação racial (IANNI, 1988). “As mediações entre determinações do racismo e determinações da sociedade de classes são, portanto, fundamentais para dar conta das sequelas que a articulação dessas determinações deixou na classe trabalhadora negra no país" (MARTINS, 2012, p.9). Dessa forma, o discurso capitalista naturaliza a exploração dos trabalhadores, principalmente no que se refere aos trabalhadores negros e negras que ocupam os piores postos e comumente encontram-se em condição de vulnerabilidade social.

A questão é saber: como essas diferenças e contradições se organizam nos discursos?

\subsection{SOBRE ANÁLISE DO DISCURSO: FORMAÇÃO DISCURSIVA, SUJEITO E IDEOLOGIA}

Atrelados aos apontamentos anteriores e dispostos a analisarmos o processo discursivo do artigo jornalístico intitulado "Eu sou racista", veiculado no jornal Folha de S. Paulo, é necessário considerarmos alguns conceitos da Análise de discurso de base pêcheutiana que se destacam como constituintes do dispositivo teórico neste trabalho.

Toda prática discursiva, por ser sócio-histórica, está inscrita em uma, ou mais de uma, formação discursiva. A heterogeneidade discursiva presente neste artigo traz a definição clássica de Pêcheux (2014, p. 147):

Chamaremos, então, formação discursiva aquilo que numa formação ideológica dada, isto é, a partir de uma posição dada, numa conjuntura dada, determina pelo estado de luta de classes, determina o que pode e deve ser dito (articulado sob a forma de uma arenga, de um sermão, de um panfleto, de uma exposição, de um programa, etc).

A formação discursiva regula o que se pode e se deve dizer em cada momento histórico e em cada espaço social, levando-se em conta condições de produção específicas, definidas historicamente. Nota-se, portanto, que ideologia e sujeito são conceitos que organizam a formação discursiva. Como não há prática discursiva sem sujeito, o acesso do sujeito enunciador à formação discursiva é regulado pela Forma-sujeito, "o chamado sujeito universal, sujeito da ciência ou do que se pretende como tal" (PÊCHEUX, 2014, p.198).

Ainda de acordo com o autor, a relação do sujeito da enunciação com o Sujeito universal pode se dar por meio de três modalidades: a) pelo recobrimento entre o sujeito da enunciação e 
o Sujeito universal da formação discursiva: caracteriza o discurso do "bom sujeito", em que há concordância plena entre essas duas instâncias discursivas, trata-se de uma tomada de posição do sujeito pautada na concordância; b) pela contraidentificação entre o sujeito do discurso e a forma-sujeito. Pêcheux (2014) denomina esse tipo de tomada de posição de discurso do "mau sujeito" por haver uma discordância parcial desse sujeito em relação aos saberes que constituem a formação discursiva que o afeta: "O resultado desta contraidentificação faz com que o sujeito do discurso, não mais se identificando plenamente aos saberes que a Forma-Sujeito representa, se relacione de forma tensa com a forma-sujeito" (INDURSKY, 2005, p.6); c) por meio da desidentificação: ocorre a não identificação total do sujeito discursivo com a formação discursiva e sua forma-sujeito; ele passa a identificar-se com outras ideologias.

A configuração da segunda e terceira modalidades indica o quanto a formação discursiva não é homogênea e fechada em si mesma. Uma formação discursiva apresenta elementos que provêm de outras formações discursivas. Esses elementos podem, por vezes, contradizê-la ou refutá-la. Dessa forma, quando o sujeito do discurso é interpelado a contraidentificar-se ou desidentificar-se de determinados sentidos, essa tomada de posição gerará uma "falha no ritual" (INDURSKY,2005, p.9) e abrirá espaço para novos sentidos, outros saberes, o esfacelamento da forma-sujeito e a mudança de posição-sujeito.

Em relação ao sujeito, a Análise de discurso (doravante $\mathrm{AD}$ ) não o considera senhor de suas intenções, ou seja, capaz de direcionar os sentidos livremente, dominando completamente o seu dizer, mas o vê como um ser dividido entre consciente e inconsciente, descentrado, afetado pela ideologia, pela história e pela posição social que ocupa.

Ao enunciar, esse sujeito está sob as determinações das formações discursivas e ideológicas a que está atrelado de forma não consciente, o que caracteriza o chamado esquecimento ideológico. Seus dizeres se constituem a partir de um trabalho relacionado a uma rede de memória, composta por dizeres já ditos e esquecidos. Para Orlandi (2000, p.35) “É da instância do inconsciente e resulta do modo como somos afetados pela ideologia. (...) os sentidos são determinados pela maneira como nos inscrevemos na língua e na história e é por isso que significam e não por nossa vontade"; além disso, por meio da ilusão referencial necessária, o sujeito do discurso acredita possuir completa consciência e poder de controle sobre tudo o que diz, o que se denomina esquecimento enunciativo: “(...) ao falarmos, o fazemos de uma maneira e não de outra e, ao longo de nosso dizer, formam-se famílias parafrásticas que indicam que o dizer sempre podia ser outro" (op. cit., p.35).

Revista Expectativa, Toledo/PR, v.20, n. 2, p. 116-134, abr./jun., 2021. 
De acordo com os pressupostos da $\mathrm{AD}$, não há discurso sem sujeito, nem sujeito sem ideologia. A fim de ressignificar discursivamente esse conceito tão polissêmico, a AD considera-o como a instância que determina como os sujeitos significam aquilo que dizem. Pêcheux vai pensar a relação entre discurso e ideologia a partir da visão estabelecida por Louis Althusser (1980).

Althusser (1996, p.29) conecta as noções de ideologia e sujeito, afirmando que "não existe prática, a não ser através de uma ideologia, e dentro dela; não existe ideologia, exceto pelo sujeito e para sujeitos". Essas reflexões o levam a concluir que "a ideologia interpela os indivíduos como sujeitos". Além disso, uma reflexão importante feita pelo autor e depois retomada e desenvolvida por Pêcheux refere-se à ideia de que os sujeitos, sem suspeitarem que estão submetidos à interpelação da ideologia, julgam-se como sendo livres e individuais:

\begin{abstract}
Decorre daí que, para vocês e para mim, a categoria do sujeito é uma "evidência" básica (as evidências são sempre básicas): é claro que você e eu somos sujeitos (livres, morais, etc.). Como todas as evidências, inclusive as que fazem com que uma palavra "nomeie uma coisa" ou "tenha um significado" (incluindo, portanto as evidências da "transparência" da linguagem), essa evidência de que você e eu somos sujeitos - e de que isso não é um problema - é um efeito ideológico, o efeito ideológico elementar (ALTHUSSER, 1996, p.30)
\end{abstract}

Segundo Portelli (1977, p.186), a importância das reflexões de Althusser sobre o tema foi diferenciar "uma teoria da ideologia geral, na qual a função da ideologia é assegurar a coesão na sociedade, da teoria das ideologias específicas, na qual a função geral já mencionada é sobredeterminada pela nova função de assegurar a dominação de uma classe.”

Inspirado pelas ideias althusserianas, que põem em destaque o efeito de "evidência" dos sentidos e dos sujeitos proporcionado pela ideologia, Pêcheux (2014) apresenta duas teses que sedimentam sua reflexão sobre ideologia do ponto de vista discursivo. Na primeira, afirma que os sentidos não existem em si mesmos, fixados a partir de uma literalidade, mas são determinados pela posição ideológica ocupada pelos sujeitos no processo sócio-histórico, ou seja, o sentido das palavras, das proposições só pode ser determinado a partir de sua inscrição em uma formação ideológica, materializada na linguagem por meio de suas relações nas já citadas formações discursivas.

Como segunda tese, o autor afirma que as formações discursivas se revestem de uma transparência dos sentidos produzida pelas formações ideológicas às quais se vinculam, ou seja, a ideologia é responsável pela produção de um processo de naturalização dos sentidos via 
"objetividade material contraditória do interdiscurso" (Op.cit., p.149). Ainda conforme Orlandi, "Este é o trabalho da ideologia: produzir evidências, colocando o homem na relação imaginária com suas condições materiais de existência" (ORLANDI, 2000, p.46).

A ideologia interpela os indivíduos em sujeitos e os faz "esquecer" que se constituem como sujeitos ideológicos. Por conta desse "esquecer" que os sentidos já estão constituídos historicamente no interdiscurso e prontos para serem convocados a circular em dada formação ideológica, os sujeitos interpretam-nos como sendo uma criação de sentido individual, circunstancial e objetiva.

Pêcheux conclui, então, que o processo de interpelação ideológica, manifestado materialmente em um discurso

\footnotetext{
fornece as evidências pelas quais "todo mundo sabe" o que é um soldado, um operário, um patrão, uma fábrica, uma greve, etc., evidências que fazem com que uma palavra ou um enunciado "queiram dizer o que realmente dizem" e que mascaram, assim, sob a "transparência da linguagem", aquilo que chamaremos o cárater material do sentido das palavras e dos enunciados (PÊCHEUX, 2014, p. 146).
}

O "caráter material do sentido" relaciona-se ao "todo complexo das formações ideológicas". Essa relação faz com que os sentidos não possam ser interpretados como se fossem presos aos seus significantes. É preciso que se leve em conta as posições ideológicas em embate no processo sócio-histórico. Vejamos como essas reflexões podem ser relacionadas à materialidade que constitui o corpus de análise.

\section{PROCEDIMENTOS METODOLÓGICOS}

Selecionamos como materialidade discursiva para análise uma crônica publicada no jornal Folha de S.Paulo, em 14/03/2020, intitulada Eu sou racista; funcionando como um subtítulo, na linha fina temos: Esse texto é um jeito de pedir socorro. Quem escreve é Tati Bernardi. Nesse contexto midiático, ela ocupa os lugares sociais de escritora e colunista do jornal, abordando, semanalmente, assuntos diversos no caderno Cotidiano.

A escolha deste texto se deu pelo chamamento feito a mim, na posição de analista, pelo título, já que o fato corriqueiro em relação ao posicionamento sobre questões raciais na sociedade é que a subjetivação do enunciador seja quase sempre negativa e não afirmativa em relação à prática do racismo.

Revista Expectativa, Toledo/PR, v.20, n. 2, p. 116-134, abr./jun., 2021. 
Dessa forma, temos como pontos de inquérito: De que forma o sujeito discursivo constrói o sentido da palavra "racista"? Como esse sujeito é afetado pela linguagem, pela ideologia e pelo inconsciente ao tratar da questão racial? De que posições esse sujeito enuncia e a quais formações discursivas e ideológicas vincula-se?

Para discutirmos sobre essas questões levaremos em conta as condições de produção sócio-históricas que envolvem, na própria construção do discurso, os embates e contradições de cunho racial no país e a não transparência dos sentidos. Isso será feito a partir da seleção de sequências discursivas (SD) que nos permitam construir um percurso que vai do fio do discurso ao discurso, para além da enunciação, atentos ao que é feito com a linguagem como prática social e ideológica.

\section{APRESENTAÇÃO E ANÁLISE DOS RESULTADOS}

As relações entre brancos e negros no país são marcadas pelas desigualdades de oportunidades geradas pelo racismo estrutural. Esse modo de constituição do racismo espraiase, de forma complexa, dos sistemas econômico, jurídico e político da sociedade até o cotidiano das relações interpessoais e familiares. Herança da escravidão longeva, configura-se num ato quase sempre atribuído ao outro, numa prática brasileira "envergonhada". O racista é um sujeito que afirma não o ser já que, na conjuntura atual, o discurso discriminatório não pode circular com a mobilidade de outrora, há restrições legais e uma certa evolução social que geram coerções. Dessa forma, o enunciado "Eu sou racista", formulado de maneira tão explícita, causa estranhamento e curiosidade e nos leva a questionar: De que posições esse sujeito enuncia? A quais formações discursivas se filia e a que ideologia vincula-se? Como constrói seu ponto de vista e que efeitos de sentido produz?

O texto em análise pode ser definido como uma crônica em que é feito um relato reflexivo. Resumidamente, trata da experiência prosaica do sujeito enunciador ao levar os filhos pequenos para mais um dia de aula em uma escola particular. Lá, ela e o marido depararam-se com a quase totalidade do corpo discente formado por alunos brancos, há apenas uma menina negra e isso os deixa bastante espantados. A partir disso, são tecidas autorreflexões sobre o assunto e o sujeito que enuncia chega à conclusão de que é racista. Quais sentidos são mobilizados para que o sujeito chegue a esse veredito?

Revista Expectativa, Toledo/PR, v.20, n. 2, p. 116-134, abr./jun., 2021. 
O fato que causa espanto e funciona como mote para o desenvolvimento de todo o texto aparece materializado pelos enunciados parafrásticos:

\section{SD (1): uma única criança negra / uma garotinha negra}

A raridade da existência de negros em entidades de ensino particular é formulada por meio do numeral cardinal uma acompanhado ou não do adjetivo única. A menina singular concretiza as dissimetrias econômicas entre brancos e negros por ser a única de sua "raça" (aqui compreendida como lugar sociológico de pertencimento) a possuir a condição financeira para frequentar um espaço elitizado, lugar de brancos. Há, portanto, além do aspecto fenotípico, uma diferença entre classes sociais que constitui esses dizeres. Isso pode ser melhor compreendido por meio da contraposição entre SD (1) e SD (2): Aquela correria alegre e saltitante de crianças brancas nos dizia tanto, em que o plural assinalado nos traz a reflexão de que escola privadas, com pequenos estudantes brancos em profusão, fazem parte de um sistema de ensino planejado para esses aprendizes, sistema inserido no modo de produção capitalista que privilegia os que participam de alguma forma do poder econômico e exclui a classe trabalhadora negra, concentrada em ocupações informais ou inserida em relações de trabalho precárias, quando não desempregada. Ao capitalismo é inerente a produção e a reprodução desse tipo de desigualdade social.

O sintagma crianças brancas traz para o discurso uma escola povoada por aqueles que são vistos como norma, os pequenos sujeitos não-étnicos, herdeiros da branquitude, conceito que diz respeito a um "construto ideológico no qual o branco se vê e classifica os não brancos a partir de seu ponto de vista. Implica vantagens simbólicas e materiais aos brancos em detrimento aos não brancos" (SILVA, 2017, p.27-28). Cabe nesse sistema, quando muito, o negro único, o negro como exceção, realidade que se repete quando o poder econômico dita as relações sociais combinada às raciais. Esses fatos corroboram a inexistência da chamada democracia racial no país, mito que se fundamenta em uma sociedade na qual não haveria diferenças entre negros e brancos e as oportunidades seriam iguais para todos, ideologia que fundamenta a meritocracia e a torna uma ideia em evidência e compartilhada socialmente.

Essa percepção do sujeito enunciador acerca da raridade da criança negra num espaço de ensino elitizado encaminha o texto para um segundo momento importante em que o sujeito enunciador, que ocupa o lugar discursivo de sujeito branco privilegiado, busca se aproximar da menininha negra, Bárbara, e interagir com ela:

Revista Expectativa, Toledo/PR, v.20, n. 2, p. 116-134, abr./jun., 2021. 
SD (3) E eu, esfuziante, dizendo que nunca tinha ouvido nome mais maravilhoso. Elogiei seu cabelo, seu sapato, seu colarzinho.

SD (4) Fui ao encontro de Bárbara movida por contentamento e também por uma necessidade de estimular aquela criança a se sentir amada e acolhida.

O modo como o sujeito se aproxima da criança é particularmente curioso: não se trata de uma abordagem feita de forma apenas "alegre" ou "animada", há um exagero na abordagem, nos elogios, uma afetação de quem se coloca em posição de superioridade em relação àquela que, segundo seu ponto de vista, deveria ser acolhida por ser única, "diferente". Como se fosse responsável pela menina, além de se aproximar dela o sujeito, de forma prepotente e artificial sente-se capaz até mesmo de amá-la, movida por um espírito de piedade. O sujeito, guiado por esse frisson, traz à luz, por meio de uma formulação inserida numa formação discursiva racista, o complexo do branco salvador. Traduzido do inglês "White savior complex" (CHEREPANOV, 2019), o complexo do branco salvador refere-se a atitudes de pessoas brancas que, por serem brancas, procuram ajudar pessoas negras ou não brancas a fim de resgatá-las da pobreza ou da vulnerabilidade, mas colocando-se, ainda que de forma inconsciente, numa posição de superioridade. É uma atitude que aparece quando celebridades, por exemplo, vão a países da África em missões humanitárias e fazem questão de postar fotos em suas redes sociais com crianças africanas miseráveis nos braços. Funciona como interdiscurso para o texto em análise, uma retomada parafrástica que reproduz um modo de agir preconceituoso várias vezes enunciado em tempos e lugares diferentes.

Entretanto, o sujeito se questiona, numa espécie de monólogo interior: SD (5) E quem disse que ela precisava disso? E quem sou eu pra achar que posso dar tudo isso para ela? Ao mesmo tempo em que está inserida numa perspectiva racista, o sujeito produz uma autocrítica, procurando repensar e se desvencilhar da atitude preconceituosa, tomada de posição que só pode ocorrer quando há a tentativa de migrar para um outro discurso e se inserir em um modo de representar a realidade de forma oposta, ou seja, quando há uma contraidentificação em relação à Forma-Sujeito que organiza esses saberes racistas. Nesse ir e vir discursivo, a partir dessas perguntas, o sujeito elege para compor o fio do discurso:

SD (6) tristeza com culpa/ culpa branca e medíocrel imbecilidade branca/minha alva cara de tacho

SD (7) sou uma babaca branca / eu sou uma completa idiota! 
As sequências discursivas materializam um deslocamento de sentido da palavra racista, já que não temos mais aqui a ideia de alguém que pratica uma "atitude hostil e discriminatória em relação a quem possui uma raça diferente", mas, sim, dizeres de um sujeito que se filiam a uma formação discursiva em que circulam saberes críticos acerca do racismo como componente estrutural da sociedade. Desse ponto de vista, o sujeito enunciador caracteriza-se a si mesmo como alguém triste, um ser culpado, medíocre, imbecil, idiota e babaca. Ora, "racistas raiz" não atribuiriam a si mesmos tais epítetos, ao contrário, elegeriam adjetivos ligados à sua superioridade em detrimento do outro. Nesse deslocamento de posição, o racista se coloca em posição de "humildade" frente ao ocorrido, estabelecendo um diálogo com o discurso religioso cristão em que está presente a responsabilidade da culpa. Entretanto, ao mesmo tempo em que tenta sublimar os erros cometidos em relação ao semelhante, seja pela autocrítica construída, seja pelo modo como vê a si mesma, consegue, no máximo, reproduzir uma atitude racista por se comportar como branca salvadora.

Outro aspecto a ser destacado nessa caracterização de si é o emprego da palavra branca acompanhando culpa e babaca. O uso do adjetivo, embora o sujeito tente se colocar em uma posição despretensiosa, carrega nos embates raciais o ponto de vista de quem está no poder, sentido construído historicamente desde o período da escravidão. O sujeito poderia ter optado por tantas outras formulações, mas trouxe para o seu discurso a memória do branco inserida nas relações raciais brasileiras. Num movimento parafrástico, isso fica ainda mais marcado no intradiscurso com a utilização da palavra alva, signo que funciona como uma gradação crescente em relação a branca. Ou seja, ao mesmo tempo em que procura enunciar de um lugar de modéstia, sua condição de privilégio ainda permanece e é reiterada, os sentidos lhe escapam, a historicidade se impõe.

Ainda sobre o modo como se reconhece, o sujeito afirma: SD (8) Eu sou a clássica "white people problems". Mantendo-se discursivamente em compasso de mea culpa por comportar-se como uma pessoa racista, o sujeito elege uma expressão estrangeira que se refere às reclamações de pessoas ricas e brancas relacionadas a problemas fúteis. A expressão circula na sociedade com um sentido irônico, atravessada pelo interdiscurso que remete às desigualdades sociais entre negros e brancos: enquanto a maioria da população negra vive na pobreza e em situações de subalternidade, os brancos da elite, em situação econômica confortável, não conseguem perceber seus privilégios nessa sociedade desigual e preocupamse muitas vezes com o que é secundário, contornável, sem importância. Parafrasticamente,

Revista Expectativa, Toledo/PR, v.20, n. 2, p. 116-134, abr./jun., 2021. 
poderia ser visto como um “mimimi”, expressão de cunho negativo que muitas vezes é atribuída aos negros quando se manifestam a respeito de situações racismo. Neste caso, teríamos um “mimimi” de branco, portanto, uma deslegitimação do próprio sujeito em relação a suas frívolas demandas sociais.

Nota-se também a relação discursiva entre política e religião, entrecruzamento que nos auxilia a compreender o modo de construção do perfil desse sujeito racista culpado:

SD (9): Pobres de nós, consumistas desenfreados de memes de esquerda e pílulas de sabedoria rápida para não apodrecer no inferno

SD (10): E isso é porque sou uma queridona legalzona de esquerda? Humana pacas?

Em SD (9), o sujeito traz para o seu dizer a companhia de outros sujeitos que parecem agir da mesma forma que a sua. Formula essa noção de conjunto por meio da inserção da primeira pessoa do plural em pobres de nós. E quem seriam esses "coitados" do discurso? E por que são vistos dessa forma pelo olhar do enunciador?

Numa relação com o político, esses sujeitos seriam aqueles que possuiriam um posicionamento situado no campo progressista o qual, no contexto atual, caracteriza-se pela luta por direitos sociais em favor de grupos historicamente preteridos, como os negros, por exemplo. Por seu caráter reivindicatório relacionado às pautas minoritárias, o Progressismo está associado aos movimentos de esquerda. Entretanto, o sujeito não concebe a si e a seus pares como membros verdadeiramente engajados nessa luta, parecem ser os chamados "esquerdistas caviar" ou "esquerdistas de boutique", que agem apenas como divulgadores de ideias que circulam pelas redes sociais, a fim de se sentirem com o dever cumprido ao se posicionarem contra o racismo como ativistas on line e não terem suas almas destinadas ao inferno por omissão. Aqui resgata-se novamente o discurso religioso, quase como numa oração de arrependimento dos brancos miseráveis de alma que agem de modo frívolo, distante nos embates raciais, sem se engajarem verdadeiramente na tentativa de mudanças estruturais, ou mesmo individuais. Pobres de nós, predicando esses sujeitos, traz a superficialidade das almas que poderiam queimar no inferno por serem tão superficiais em relação às questões raciais.

Em SD (10), agora de volta à primeira pessoa gramatical, a condição política do sujeito é reafirmada, configurando-se como uma regularidade no discurso. Ao formular um novo questionamento, acaba relacionando a ideia de esquerda à humanidade, ou seja, progressistas seriam mais sensíveis, mais humanos em relação aos problemas sociais. No entanto, como essa reflexão vem em forma de pergunta, tais dizeres materializam a incerteza do sujeito pois,

Revista Expectativa, Toledo/PR, v.20, n. 2, p. 116-134, abr./jun., 2021. 
embora ela possua esse perfil, ainda pratica atitudes racistas. Tal questionamento ganha um efeito de sentido irônico pelo emprego do sufixo -ona (legalzona, queridona) e da gíria já em desuso, pacas, intensificando um zombar de si mesma. No entanto, como essa reflexão vem em forma de pergunta, tais dizeres materializam a incerteza do sujeito, pois, embora ela possua esse perfil, ainda pratica atitudes racistas.

Evocando o discurso da História, temos em SD (11): Meus antepassados racistas deixaram uma dívida tão infinita que nem 100 bilhões das minhas risadas e delicadezas pagariam. O sujeito traz para a construção dos sentidos a memória discursiva do período escravagista, em que aos negros era negado o pertencimento à condição humana. $\mathrm{O}$ sujeito vincula seu agir racista a uma linhagem de pessoas preconceituosas (antepassados), ou seja, trata-se de uma visão e de um comportamento transmitidos por gerações, o que demonstra o quão estrutural é o racismo no Brasil. Entretanto, apresenta um discurso ambíguo: ao mesmo tempo que faz parte do sistema e se vale dele, procura compreendê-lo e negá-lo, na tentativa de desvincular-se desse modo de pensar e agir. Os esquecimentos enunciativo e ideológico, no entanto, fazem com que formule suas ideias por meio de construções sintáticas que deixam escapar pontos de vista distintos do que ela parece pretender apresentar ao leitor do jornal:

SD (12) Lamentamos o mundo ser assim e, ao mesmo tempo, nos incluímos nas pústulas do país em que vivemos.

SD (13) ...ou estávamos na escola errada ou erramos ininterruptamente por mais de cem anos e ainda não aprendemos nada com isso.

Por terem se deparado com a única menina negra da escola, como já vimos, a sensação do sujeito foi de espanto. Entretanto, sequencialmente a esse fato, ao selecionar o verbo lamentar para compor o seu dizer, conjugado na primeira pessoa do plural, o sujeito coloca-se a si a seu par em uma posição de passividade, como se nada pudessem fazer para colaborar com iniciativas de cunho antirracistas a não ser ficarem tristes ou chateados com a situação. Ressaltando essa ideia de apatia, há o uso do verbo ser, no infinitivo impessoal, escolha que constrói a ideia de que a formação social brasileira, marcada pelo racismo, nasceu de modo espontâneo, algo inevitável. Dito de outra forma, o discurso silencia todo processo violento de escravização do negro inserido em um regime social, político e econômico, é como se não houvesse atores responsáveis pela construção de uma estrutura social desigual em que se entrecruzam as variáveis raça e classe social despossuída, gerada por quase quatro séculos de exploração escravista. É uma formulação que evoca uma espécie de eternidade dos fatos, 
posicionamento que obriga o sujeito a deixar de lado toda historicidade. Considera o sistema apodrecido, mas o máximo que podem fazer é lamentar.

Nessa alternância de posições, em SD (13), a fim de ensaiar uma argumentação para justificar as dissimetrias raciais, o sujeito emprega a conjunção alternativa ou...ou na perspectiva disjuntiva exclusiva. Contudo, ao lançar mão dessa construção sintática, novamente vai de encontro à imagem politicamente correta de racista que pretende construir discursivamente. Isto ocorre porque as ideias apresentadas em forma de alternância não se excluem, uma não está em detrimento da outra, ao contrário, coexistem na estrutura social brasileira. Portanto, sim, eles estavam na escola errada, pois uma escola correta faria parte de um sistema socioeconômico capaz de incluir pobres e ricos, entendendo pobres como a maioria da população negra do país; e sim há um erro histórico com o qual grande parcela da população compactua, tanto em nível jurídico, político quanto econômico, esferas que asseguram a lenta mobilidade social para que não haja abalos radicais que as modifiquem. A relação estabelecida em forma de disjunção deveria constituir-se, na verdade, numa perspectiva de efeito e causa, mas a historicidade dos sentidos e os esquecimentos traem os sujeitos.

\subsection{UNINDO AS PONTAS DO DISCURSO}

Para darmos conta do processo discursivo, retomamos as questões que funcionam como pontos de inquérito: De que forma o sujeito discursivo constrói o sentido da palavra "racista"? Como esse sujeito é afetado pela linguagem, pela ideologia e pelo inconsciente ao tratar da questão racial? De que posições esse sujeito enuncia e a quais formações discursivas e ideológicas vincula-se?

Proclamar-se racista exigiu do sujeito discursivo um deslocamento do sentido já cristalizado pela repetibilidade dessa palavra em discursos dispersos no tempo e no espaço. Pertencente a Formações discursivas racistas e, por isso, empregada inúmeras vezes em condições de produção sócio-históricas em que o ódio racial é reverberado, nesta conjuntura específica deriva seu sentido para "aquele que se reconhece como possuidor de preconceitos de raça e se coloca em reflexão a respeito do assunto". Nesse processo metafórico de constituição de sentidos, ocupa posições-sujeito diferentes e contraditórias. A primeira denominaremos racista arrependido; a segunda, racista raiz.

Revista Expectativa, Toledo/PR, v.20, n. 2, p. 116-134, abr./jun., 2021. 
Ao ocupar a primeira posição, o sujeito inscreve-se em uma Formação discursiva na qual entrecruzam-se dizeres que circulam em discursos provenientes da religião cristã e da política. Como vimos na análise das sequências discursivas, é um sujeito que vê a si como culpado e, para expiar de alguma forma suas culpas, coloca-se em posição de humildade pelos erros cometidos contra os seus semelhantes no que concerne às questões raciais. Ironiza seu posicionamento político de esquerda, progressista, como incapaz de fazê-la um ser humano mais comprometido com a causa e menos ativista de internet. Por meio dos recortes, entretanto, pode-se observar a superficialidade e a fragilidade de uma discussão que procura de inscrever em uma formação ideológica antirracista.

Sem se dar conta, desloca-se para a segunda posição-sujeito, a de racista raiz, ao silenciar os aspectos econômicos do discurso capitalista que devem engendrar e sustentar as discussões a respeito de raça no país. Isso se dá nas passagens em que reafirma questões de poder, reiterando os adjetivos branca/alva, ao colocar problemas sociais que funcionam na perspectiva de causa e efeito de maneira a excluírem-se e ao utilizar o verbo no infinitivo, gerando um sentido de eternidade para a existência do racismo. Nessa tomada de posição, o sujeito desidentifica-se dos saberes presentes na formação discursiva anterior, ocupando uma posição distinta. A forma-sujeito que mobiliza os conhecimentos desta formação ideológica vincula-se a uma ideologia racista, em que a inação, e a falta de compreensão dos processos econômicos/raciais não são questionados, mas vistos de forma evidente por si mesmos e naturalizada

Dessa forma, observa-se a coexistência de discursos antagônicos na tentativa de unificar contradições sociais/raciais: embora o sujeito busque inserir-se numa perspectiva antirracista, já que se questiona no decorrer do texto a respeito de suas próprias atitudes, é convocado pelo esquecimento ideológico e acaba materializando saberes próprios da formação ideológica oposta. Essa transição de uma posição-sujeito a outra ocorre de forma muito sutil, sofisticada, pois o sujeito está inserido num processo de reprodução de condições sociais, políticas e econômicas que naturaliza as desigualdades. Da mesma forma que busca ser aliado da causa antirracista, o sujeito resvala, tropeça nos discursos que o formam a partir de sua identidade branca, membro de um grupo social economicamente privilegiado. Neste momento, a ideologia racial dominante se impõe.

Revista Expectativa, Toledo/PR, v.20, n. 2, p. 116-134, abr./jun., 2021. 


\section{CONSIDERAÇÕES FINAIS}

Alcançamos o processo discursivo e estão respondidos, portanto, nossos pontos de inquérito anteriormente enunciados. Discursos que se referem a aspectos raciais apresentam um funcionamento complexo, pois constituem-se de modo heterogêneo e criam uma teia interdiscursiva intrincada propensa a falhas e contradições. Examinamos de forma detida as posições ocupadas pelo sujeito discursivo, que ocupa o lugar social de uma mulher branca, escritora, que enuncia do ponto de vista da elite econômica em uma coluna de jornal de grande circulação, e pudemos desvelar a dubiedade de seu posicionamento discursivo ora filiado a uma formação discursiva antirracista, ora identificado à posição do racista tradicional.

As condições sócio-históricas atuais permitem novas possibilidades do dizer acerca do racismo. No caso em tela, temos a tentativa de desconstrução social de um sujeito discursivo branco que se considera racista nas formações imaginárias, ainda que essa discussão esteja alicerçada em bases um tanto superficiais. $\mathrm{O}$ racismo à brasileira funciona para além dos discursos de ódio explícito. O silêncio e a omissão também discursivizam atitudes racistas, colaborando para uma cultura de morte.

\section{REFERÊNCIAS}

ALMEIDA, Sílvio. Racismo estrutural. São Paulo: Pólen, 2019.

ALTHUSSER, Louis. Ideologia e aparelhos ideológicos de Estado: notas para uma investigação. In: ZIZEK, Slavoj (org). Um mapa da ideologia. Trad. Vera Ribeiro. Rio de Janeiro: Contraponto, 1996.

CHEREPANOV, Elena. Ethics for Global Mental Health: from good intentions to humanitarian accountabillity. New York: Routleged, 2019.

DOMINGUES, Petrônio José. Uma história não contada: negro, racismo e branqueamento em São Paulo no Pós-Abolição. São Paulo: Senac, 2004.

FERNANDES, Florestan. O negro no mundo dos brancos. 1. Ed. digital. São Paulo: Global, 2013.

HALL, Stuart. Raça, o significante flutuante. Z cultural: revista do programa avançado de cultura contemporânea. Tradução de Liv Sovik, em colaboração com Katia Santos.

Universidade Estadual do Rio de Janeiro. Conferência proferida por Stuart Hall em 1995, em Goldsmiths College University of London. Disponível em:

http://revistazcultural.pacc.ufrj.br/raca-o-significante-flutuante\%EF\%80\%AA/. Acesso em: 15 jun. 2020.

Revista Expectativa, Toledo/PR, v.20, n. 2, p. 116-134, abr./jun., 2021. 
IANNI, Octávio. Escravidão e racismo. 2. ed. São Paulo: Hucitec, 1988.

INDURSKY, Freda. Formação Discursiva: ela ainda merece que lutemos por ela? Universidade Federal do Rio Grande do Sul, II SEAD - Seminários de Estudo de Análise de Discurso, 2005.

MARTINS, Tereza Cristina Santos. O negro no contexto das novas estratégias do capital: desemprego, precarização e informalidade. Revista Ser Social, São Paulo, n. 111, p. 450-467, jul./set. 2012.

MUNANGA, Kabengele. As ambiguidades do racismo à brasileira. In: KON, Noemi Moritz; SILVA, Maria Lúcia da; ABUD, Cristiane Curi. O racismo e o negro no Brasil: questões para a Psicanálise. São Paulo: Perspectiva, 2017. p. 33-44.

MUNANGA, Kabengele. Uma abordagem conceitual das questões de raça, racismo, identidade e etnia. In: SEMINÁRIO NACIONAL DAS RELAÇÕES RACIAIS E EDUCAÇÃO-PENESB, 3. Rio de Janeiro, 5 de nov. 2003. Palestra proferida no evento. Disponível em: https://www.geledes.org.br/wp-content/uploads/2014/04/Uma-abordagemconceitual-das-nocoes-de-raca-racismo-dentidade-e-etnia.pdf. Acesso em: 15 jun. 2020.

ORLANDI, Eni Pucinelli. Análise de discurso: princípios e procedimentos. 2. ed. Campinas: Pontes, 2000.

PORTELLI, Hugues. Gramsci e o bloco histórico. Tradução de Angelina Peralva. Rio de Janeiro: Paz e Terra Editora, 1977.

PÊCHEUX, Michel. Semântica e discurso: uma crítica à afirmação do óbvio. 5. ed. Campinas: Editora da Unicamp, 2014.

SCHWARCZ, Lilia Moritz. Nem preto nem branco, muito pelo contrário: cor e raça na intimidade. In: NOVAES, Fernando (org). História da vida Privada no Brasil. São Paulo: Cia de Letras, 1998.

SILVA, Priscila Elizabete da. O conceito de branquitude: reflexões para o campo de estudo. In: MULLER, Tânia M. P.; CARDOSO, Lourenço (orgs). Branquitude: estudos sobre a identidade branca no Brasil. Curitiba: Appris, 2017.p.19-30.

SODRÉ, Muniz. Do lugar de fala ao corpo como lugar de diálogo: raça e etnicidades numa perspectiva comunicacional. Reciis - Rev Eletron Comun Inf Inov Saúde, v. 13, n. 4, p. 877-886, out./dez. 2019.

WIEVIORKA, Michel. O racismo, uma introdução. São Paulo: Perspectiva, 2007.

\section{Texto analisado:}

BERNARDI, Tati. Eu sou racista. Disponível em:

https://www1.folha.uol.com.br/colunas/tatibernardi/2020/02/eu-sou-racista.shtml. Acesso em 30 maio 2020. 